\title{
Case Report: Aortic Root Abscess with a Left Ventricular Outflow Tract Tunnel
}

\author{
Prem Krishna Anandan* , Patel Jigarkumar shukkarbhai, Prabhavathi, \\ Cholenahally Nanjappa Manjunath, Dhanalakshmi.C.
}

Sri Jayadeva Institute of Cardiovascular Science \& Research, India

Copyright (C) 2015 Horizon Research Publishing All rights reserved.

\begin{abstract}
Aortic root abscess is one of the dreaded complications of aortic valve infective endocarditis. It carries a very high morbidity and mortality. Early diagnosis and surgical treatment is the main key. Echocardiography aids in early detection of this complication. We report a 22 year old male patient of bicuspid aortic valve with native aortic valve endocarditis complicated with formation of aortic root abscess and severe aortic regurgitation(AR) through an Left ventricular outflow tract(LVOT) tunnel.
\end{abstract}

Keywords Infective Endocarditis, Aotic Root Abscess, Native Aortic Valve

\section{Case Summary}

A 22 years old male, presented with history of fever for the past 3 months. He was diagnosed to have a cardiac murmur by a physician and was referred to our institute for evaluation. Patient had worsening dyspnea with episodes of Paroxysmal nocturnal dyspnea for the past 5 days. There was no past history of rheumatic fever, neither any history of IV drug abuse. He was not a known hypertensive or diabetic. On examination, the patient was pale, thin built(BMI 17 $\mathrm{Kg} / \mathrm{m} 2$ ), febrile(101 F) with Grade 2 clubbing, with a pulse rate of 110/min and BP 140/30mmHg.Cardiac examination revealed a soft S1,LV S3, grade 3 Early diastolic murmur at second left intercostal space and a grade $2 / 6$ ejection systolic murmur in the aortic area. His investigations revealed $\mathrm{Hb}-$ $8 \mathrm{gm} / \mathrm{dl}$, Total Leucocyte Count - 22000/ml with $85 \%$ Neutrophils .ECG showed LVH with volume overload pattern. Chest $\mathrm{X}$ ray showed cardiomegaly with pulmonary venous congestion.2D echo showed a bicuspid aortic valve with vegetation on the right coronary cusp with an aortic root abscess causing severe AR. The AR jet was tunneling through the abscess into LV cavity(FIG 1,2,3).LV systolic function was reduced with dilated chambers. Blood cultures showed growth of staphylococcus aureus sensitive to vancomycin. Patient was started on iv antibiotics and underwent urgent successful aortic valve replacement.

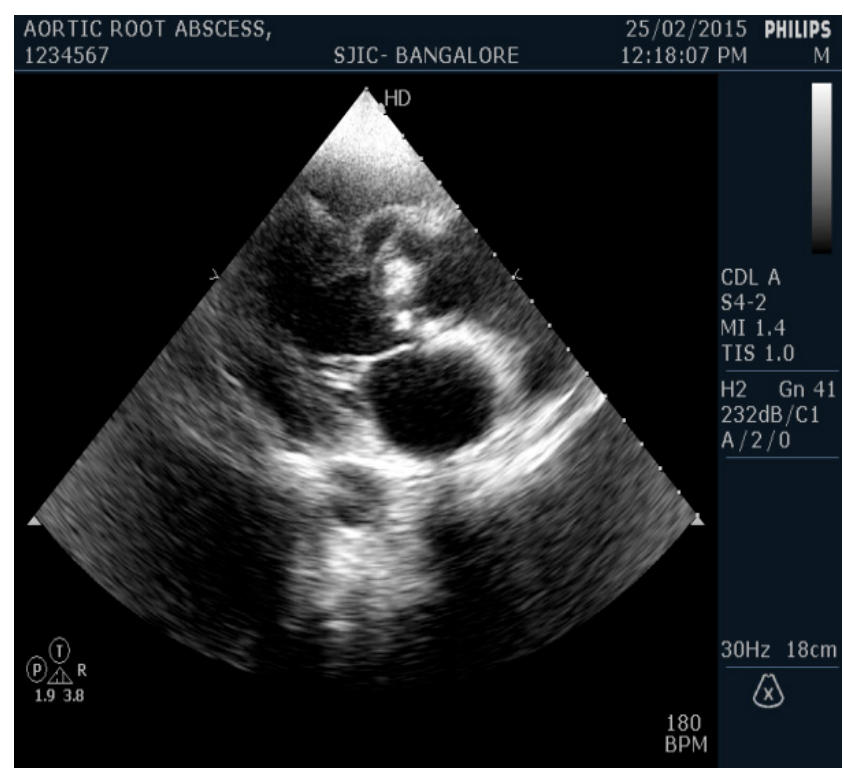

Figure 1. parasternal long axis(PLAX) view showing vegetation on Aortic valve with an abscess

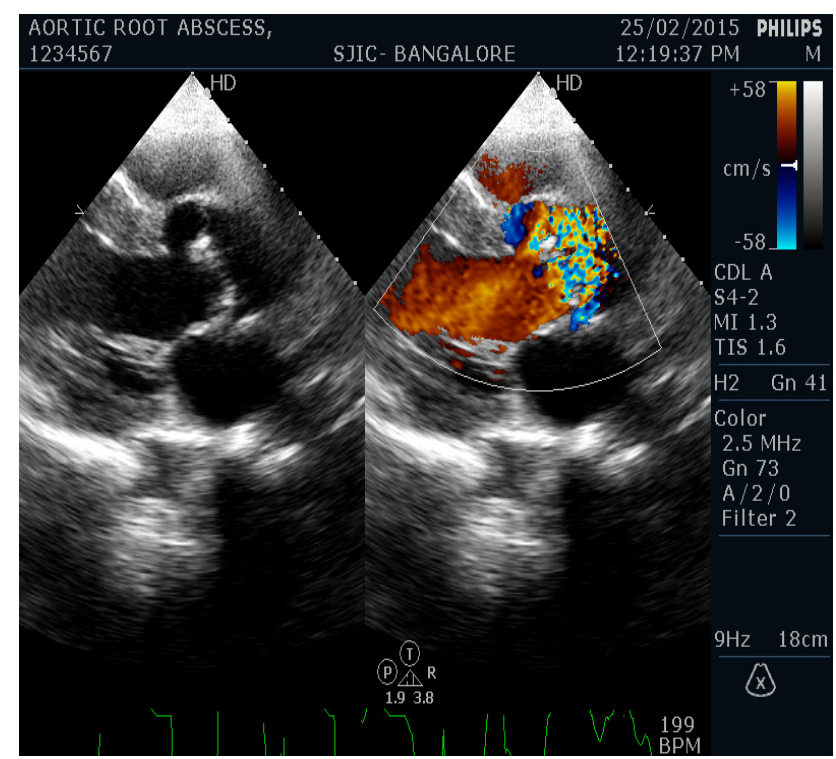

Figure 2. PLAX view showing AR jet traversing through the abscess cavity in LVOT into LV 


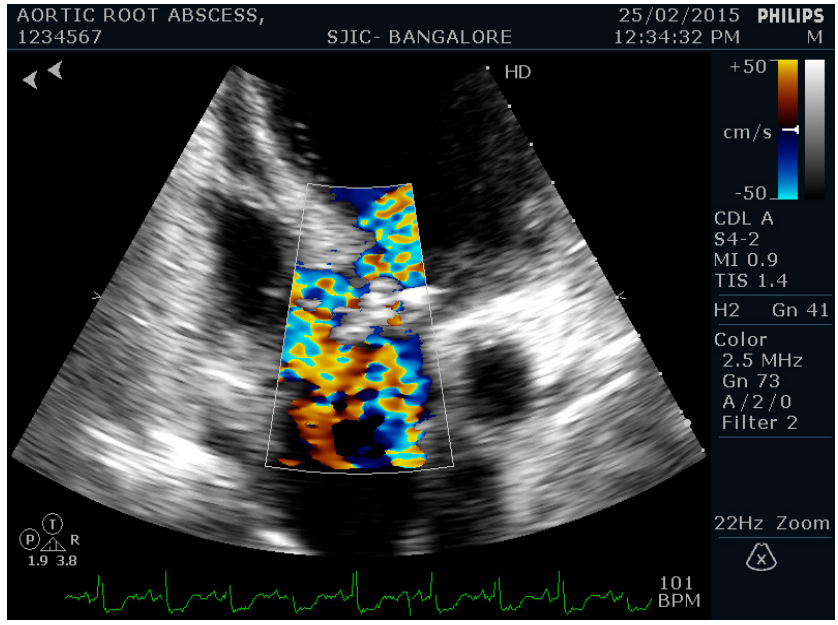

Figure 3. Magnified PLAX view showing AR jet traversing through the abscess cavity in LVOT into LV

\section{Discussion}

S. aureus is a common cause of both native and prosthetic valve endocarditis.[1,2] The presentation in cases caused by $\mathrm{S}$. aureus is acute in onset and associated with considerable systemic toxicity. In cases of left-heart infection, morbidity and mortality rates are high, despite appropriate therapy including surgical intervention. Perivalvular extension in IE includes the complications like periannular or intramyocardial abscess, mycotic false aneurysm, and fistula. The incidence of perivalvular extension ranges from $10 \%$ to $30 \%$ in native valve IE and $30 \%$ to $55 \%$ in prosthetic valve endocarditis[3] .Valve annular involvement in IE occurs by direct extension because the relatively avascular anulus offers little resistance to infection (4).Aortic root abscess may cause persistent sepsis, heart failure, conduction abnormalities, fistula formation (5).

Aortic root abscess should be suspected in any patient with aortic valve endocarditis who fails to improve within 72 hours on appropriate antibiotics, who develop conduction disturbances like heart blocks. Transthoracic echocardiography (TTE) can give useful information about vegetations, the haemodynamic consequences of valvular regurgitation, and presence of aortic root abscess (6). The sensitivity of TTE for the diagnosis of perivalvular extension is at best $50 \%$, and even less in cases of prosthetic valve endocarditis. Imaging with TEE has a reported sensitivity of $80 \%$ to $90 \%$, specificity of greater than $90 \%$.Cardiac CT has $96 \%$ sensitivity in detecting valvular vegetations, identical in this respect to multiplane TEE, in comparison with surgery.[7] Attention should be directed by TTE to the sub-aortic zone of the Mitral-Aortic intervalve fibrous region(MAIF) and the Anterior mitral leaflet(AML) in every patient with endocarditis of the aortic valve. Any thickening at the base of the mitral leaflet or the posterior aortic root, especially in the presence of an eccentric mitral regurgitation jet by color flow imaging, should alert the clinician to the possibility of these complications. Trans-esophageal echocardiography (TEE) provides useful anatomical definitions like the extent of annular involvement, extension of abscess to involve the sub-aortic curtain or upper inter-ventricular septum and for planning surgery in these patients (8). Because of its proximity to the mitral valve, a left ventricular outflow tract to left atrial communication must be differentiated from valvular vegetation and ruptured sinus of Valsalva aneurysm. Once an aortic root abscess is detected, urgent surgery is required. Aggressive debridement of all infected and devitalized tissue is the mainstay of the surgical treatment of aortic root abscess. Reconstruction of the left ventricular outflow tract with autologous pericardium or translocation of the aortic valve may also be required. Aortic valve homo-grafts are particularly useful for several reasons: they enable the abscess cavity to be completely excluded from the circulation; they avoid the use of prosthetic material; and they are more resistant to infection than any other valve substitute (9). Rapid and accurate detection of an abscess complicating endocarditis may reduce the increased morbidity and mortality associated with its presence(10). Even when successfully diagnosed, an abscess presents surgical problems. Sutures placed deeply into the ventricular septum in an attempt to obliterate an erosive aortic abscess can produce heart block (11). Also, sutures in the aortic anulus and mitral-aortic intervalvular fibrosa region can cause valvular regurgitation .

\section{Conclusions}

Aortic abscess is an important devastating complication of both native and prosthetic valve endocarditis. Prompt recognition and urgent surgery is the key to successful management.

\section{Conflict of Interests}

The authors declare that there is no conflict of interests.

\section{REFERENCES}

[1] Baddour LM, Wilson WR, Bayer AS, et al: Infective endocarditis: Diagnosis, antimicrobial therapy, and management of complications. Circulation 111:e394, 2005.

[2] Murdoch DR, Corey GR, Hoen B, et al: Clinical presentation, etiology, and outcome of infective endocarditis in the $21 \mathrm{st}$ century: The International Collaboration on Endocarditis-Prospective Cohort Study. Arch Intern Med 169:463, 2009

[3] Graupner C, Vilacosta I, San Roman JA, et al: Periannular extension of infective endocarditis. J Am Coll Cardiol 39:1204, 2002.

[4] Ryon DS, Pastor BH, Myerson RM. Abscess of the 
myocardium. Am J Med Sci 1966;251:698-705

[5] Prashanth Panduranga Hindawi Publishing Corporation Case Reports in Critical Care Volume 2013, Article ID 636519, 3 pages http://dx.doi.org/10.1155/2013/636519

[6] Wong CM, Oldershaw P, Gibson DG(1981) Echocardiographic demonstration of aortic root abscess after infective endocarditis. Br Heart J 46:584-586.

[7] Feuchtner GM, Stolzmann P, Dichtl W, et al: Multislice computed tomography in infective endocarditis. J Am Coll Cardiol 53:436, 2009

[8] Wong CM, Oldershaw P, Gibson DG. Echocardiographic demonstration of aortic root abscess after infective endocarditis. Br Heart J 1981;46:584-6.

[9] Stinson EB. Surgical treatment of infective endocarditis. Prog Cardiovasc Dis 1979;22:145-68.

[10] Crosby IK, Carrell R, Reed WA. Operative management of valvular complications of bacterial endocarditis. J Thorac Cardiovasc Surg 1972;64:235-46.

[11] Buckley MJ, Mundth ED, Daggett WM, Austen WG. Surgical management of the complications of sepsis involving the aortic valve, aortic root, and ascending aorta. Ann Thorac Surg 1971;12:391-9. 